\title{
Helicobacter pylori and associated duodenal ulcer
}

\author{
C K Yeung, K H Fu, K Y Yuen, W F Ng, T M Tsang, F J Branicki, H Saing
}

\begin{abstract}
Twenty three children with coexistent duodenal ulcer and Helicobacter pylori infection were treated with either two weeks of amoxycillin $(25 \mathrm{mg} / \mathrm{kg} /$ day) in addition to six weeks of cimetidine, or cimetidine alone. Endoscopy with antral and duodenal biopsies for urease test, microaerophilic culture, and histological studies were performed at entry, six weeks, 12 weeks, and at six months. Children with persistent $H$ pylori infection at six weeks were given a further two weeks' course of amoxycillin. $H$ pylori persisted in all children not receiving amoxycillin treatment but cleared in six of the 13 children $(46 \%)$ treated with amoxycillin. With failure of $H$ pylori clearance at six months, only two out of six (33\%) ulcers had healed and $50 \%$ of patients had experienced ulcer recurrence. In contrast, when $H$ pylori remained cleared all ulcers healed and no ulcer recurred. Persistent $H$ pylori infection was associated with persistent gastritis and duodenitis despite endoscopic evidence of ulcer healing. Detection and eradication of $\boldsymbol{H}$ pylori deserves particular attention in the routine management of duodenal ulceration in children.
\end{abstract}

The association between the presence of Helicobacter pylori in antral mucosa and histological gastritis has now been well established both in adults ${ }^{12}$ and children. ${ }^{3}{ }^{4}$ It has also been shown in adults that $H$ pylori infection plays an important part in the healing and relapse of duodenal ulcer. ${ }^{5}$ Similar studies are, however, lacking in children and the above association between $H$ pylori infection and duodenal ulceration in the paediatric population still requires clarification. This report documents a prospective study to evaluate the clinical, endoscopic, microbiological, and histological features of duodenal ulcer associated with $H$ pylori in children after amoxycillin treatment.

\section{Patients and methods}

Twenty three children (mean age $11 \cdot 2$ years, range 4-16) diagnosed endoscopically to have duodenal ulcer with coexistent isolation of $H$ pylori from the gastric and/or duodenal mucosa were entered into the study. There were 15 boys and eight girls. Ten children had a history of upper gastrointestinal bleeding, and in 13 upper endoscopy had been undertaken for recurrent upper abdominal pain of three or more months' duration. Patients in whom gastric or duodenal biopsy was contraindicated and those who had recently completed an antibiotic course before endoscopy were excluded from the study. Written informed consent was obtained from parents before inclusion.

\section{ENDOSCOPY AND BIOPSY}

Endoscopic examinations were performed using a paediatric forward viewing gastroscope (Olympus GIF XP or GIF P2). Acute duodenal ulcers with no endoscopic evidence of chronicity (that is, deep lesions with fold convergency and bulb deformity) were included in the study but superficial mucosal erosions and ulceration secondary to steroids, stress, etc, were excluded. Two gastric mucosal biopsy specimens were taken from the antrum at $1-2 \mathrm{~cm}$ from the pylorus. The first specimen was divided into two portions. One portion was immediately ground in the endoscopy room for the rapid urease test using $1 \mathrm{ml}$ of freshly prepared $10 \%$ urea solution, ${ }^{6}$ and the other was despatched immediately for microbiological smear and culture. The second biopsy specimen was fixed in formol saline for histological section. Two mucosal biopsy specimens were also taken from the duodenal cap adjacent to the ulcer and were processed in a similar manner to the gastric biopsy specimens.

\section{HISTOLOGY}

Histological sections of the specimens were stained with haematoxylin and eosin for grading of gastritis and duodenitis, and with WarthinStarry stain to demonstrate the bacteria. Antral gastritis was graded according to the criteria of Whitehead et al, ${ }^{7}$ depending on the presence or absence of polymorphonuclear leucocytes and the intensity of inflammatory cell infiltration. Active chronic gastritis (polymorphonuclear leucocytes present) was graded with scores from 0-3 (absent, mild, moderate, severe). A score of 0-3 was also assigned for duodenitis according to the classification described by Wyatt et al (table 1). ${ }^{8}$

\section{MICROBIOLOGY}

A portion of the specimen was examined by Gram stain and it was then inoculated after grinding onto a brain heart infusion agar with vancomycin, nalidixic acid, and amphotericin $B$ within three hours of collection. The plates were incubated at $37^{\circ} \mathrm{C}$ in a microaerophilic environment and examined at the fourth and seventh day before being discarded.

All laboratory investigations were conducted 
Table 1 Grading of duodenitis

\begin{tabular}{lll}
\hline Grade & Degree of duodenitis & Histological features \\
\hline $\mathbf{0}$ & $\begin{array}{l}\text { Normal } \\
\text { Insignificant duodenitis }\end{array}$ & $\begin{array}{l}\text { Normal duodenal architecture } \\
\text { Architectural changes only with no definite increase in inflammatory cells } \\
\text { Definite increase in mononuclear cells in the lamina propria with evidence of epithelial } \\
\text { degeneration }\end{array}$ \\
$\mathbf{2}$ & $\begin{array}{l}\text { Chronic duodenitis } \\
\text { Changes of chronic duodenitis plus presence of intraepithelial neutrophils }\end{array}$ \\
\hline
\end{tabular}

without prior knowledge of endoscopy findings, treatment regimen or $H$ pylori state. A patient was defined as $H$ pylori positive if the bacteria were identified either by histological examination or culture, and $H$ pylori negative if the bacteria were not detected.

\section{TREATMENT REGIMEN}

A decision regarding treatment was made immediately after endoscopy according to the result of the urease test. $H$ pylori was assumed to be present when a biopsy specimen showed a positive urease test as indicated by a definite colour change from yellow to pink within five minutes. Patients with a positive result were then randomly assigned to receive either two weeks of amoxycillin $(25 \mathrm{mg} / \mathrm{kg} /$ day in three divided doses) in addition to a six week therapeutic course of cimetidine $(20 \mathrm{mg} / \mathrm{kg} / \mathrm{day}$ in three divided doses), or cimetidine alone. All patients with a positive urease test had $H$ pylori infection confirmed subsequently on histological examination or culture, and no patient was removed from the study with a false positive urease result.

Endoscopy with antral and duodenal biopsies for urease test, microaerophilic culture, and histological studies were repeated immediately after six weeks' treatment and again at 12 weeks. All patients with $H$ pylori detected again at six weeks received a further two week course of amoxycillin. In addition, patients with unhealed or partially healed ulcers were given

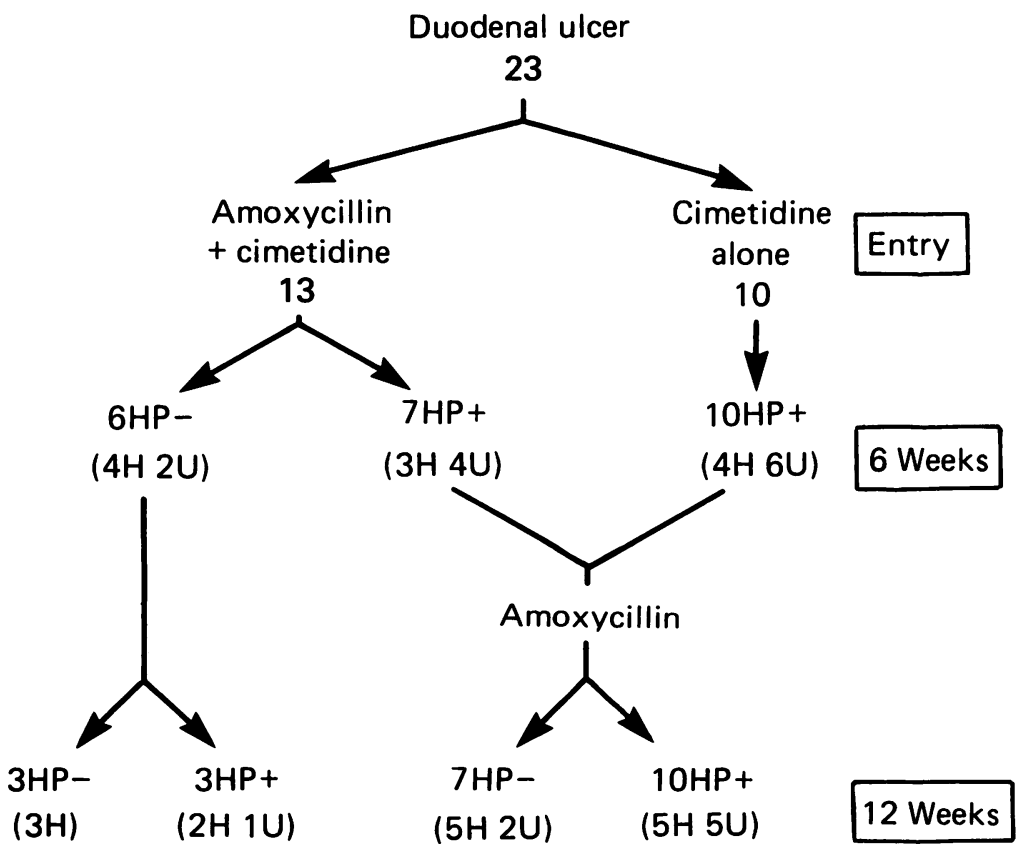

Figure 1 Treatment regimen, $H$ pylori state, and ulcer healing $(H=u l c e r$ healed, $U=u l c e r$ unhealed, $H P-=H$ pylori negative, $H P+=H$ pylori positive). further six week courses of cimetidine until complete healing was achieved. Maintenance treatment with nocturnal dosage of cimetidine, $10 \mathrm{mg} / \mathrm{kg}$, was given only to patients who required more than one therapeutic course of cimetidine for complete ulcer healing. Follow up endoscopy and biopsy were repeated again at six months after entry.

\section{STATISTICAL ANALYSIS}

Data analyses were performed using the $\chi^{2}$ test with Yates's correction and the Wilcoxon test, $p$ values of $<0.05$ were considered to be significant.

\section{Results}

\section{EFFICACY OF TREATMENT FOR H PYLORI} ERADICATION

All 23 children completed 12 weeks of treatment, although three were lost to follow up at six months. For the first six weeks of treatment, 13 children received two weeks of amoxycillin with cimetidine, whereas the remaining 10 children were given cimetidine alone (fig 1). Endoscopy and biopsy after six weeks treatment showed that six of 13 children $(46 \%)$ who received amoxycillin became $H$ pylori negative. In contrast, all 10 children not receiving amoxycillin remained positive $(p<0.02)$

The 17 children who remained positive at the end of six weeks were given a further two week course of amoxycillin. Seven of these 17 (41\%) became negative and 10 remained positive for $H$ pylori on endoscopy at 12 weeks. Of six children with initial clearance at six weeks, three remained negative and three were found to have a relapse of $H$ pylori infection.

Twenty children were available for follow up at six months. Four of 10 children with clearance of $H$ pylori at 12 weeks had a relapse of infection and only six remained negative after initial clearance. Of 10 children with $H$ pylori infection at 12 weeks, only one child had spontaneous clearance of $\boldsymbol{H}$ pylori and nine remained positive. Six of these nine children were persistently infected throughout the study period without clearance of $H$ pylori.

\section{ULCER HEALING AND SYMPTOMATIC RELIEF}

(TABLE 2)

After the first six week treatment period, four of six children who were then negative had healed their ulcers whereas only seven of $17(41 \%)$ children still positive had endoscopic ulcer healing $(p>0 \cdot 2)$. On repeat endoscopy at 12 weeks, ulcer healing had taken place in eight of 10 children in the negative group compared with only seven of 13 children $(54 \%)$ in the positive group $(p>0 \cdot 15)$. On follow up at six months all six children who remained negative after initial 
Table 2 Clinical, endoscopic, and histological changes with clearance of $H$ pylori after amoxycillin treatment

\begin{tabular}{|c|c|c|c|c|c|c|c|}
\hline & \multirow{2}{*}{$\begin{array}{l}\text { At } \\
\text { entry }\end{array}$} & \multicolumn{2}{|c|}{$H$ pylori at 6 weeks } & \multicolumn{2}{|c|}{$H$ pylori at 12 weeks } & \multicolumn{2}{|c|}{$H$ pylori at 6 months } \\
\hline & & Negative & Positive & Negative & Positive & Negative & Positive \\
\hline $\begin{array}{l}\text { No of children } \\
\text { Ulcer symptoms present }\end{array}$ & $\begin{array}{l}23 \\
17\end{array}$ & $\begin{array}{l}6 \\
1\end{array}$ & $\begin{array}{r}17 \\
8\end{array}$ & $\begin{array}{r}10 \\
2\end{array}$ & $\begin{array}{c}13 \\
8^{*}\end{array}$ & $\begin{array}{l}7 \\
0\end{array}$ & $\begin{array}{l}13 \\
6^{*}\end{array}$ \\
\hline $\begin{array}{l}\text { Endoscopic findings: } \\
\text { Nodular antritis } \\
\text { Ulcer healed } \\
\text { Ulcer unhealed }\end{array}$ & $\begin{array}{r}11 \\
0 \\
23\end{array}$ & $\begin{array}{l}1 \\
4 \\
2\end{array}$ & $\begin{array}{r}7 \\
7 \\
10\end{array}$ & $\begin{array}{l}2 \\
8 \\
2\end{array}$ & $\begin{array}{l}4 \\
7 \\
6\end{array}$ & $\begin{array}{l}\mathbf{0} \\
7 \\
\mathbf{0}\end{array}$ & $\begin{array}{l}5 \\
8 \\
5\end{array}$ \\
\hline $\begin{array}{l}\text { Histological findings: } \\
\text { Active chronic gastritis } \\
\text { Significant duodenitis (grade } 2 \text { and } 3 \text { ) }\end{array}$ & $\begin{array}{l}23 \\
14\end{array}$ & $\begin{array}{l}2 \\
3\end{array}$ & $\begin{array}{l}16^{*} \\
10\end{array}$ & $\begin{array}{l}3 \\
1\end{array}$ & $\begin{array}{l}12^{*} \\
7^{*}\end{array}$ & $\begin{array}{l}3 \\
1\end{array}$ & $\begin{array}{r}13^{*} \\
8^{*}\end{array}$ \\
\hline
\end{tabular}

Numbers in parentheses denote ulcer recurrence.

${ }^{*}$ Significant difference $(p<0.05)$ between positive and negative groups.

clearance had healed ulcers. In contrast, ulcers had healed in only two of six children with persistent $H$ pylori infection throughout the study period $(\mathrm{p}<0.02)$.

Only one child who was negative for $H$ pylori at six weeks had persistent abdominal pain compared with eight who were positive $(p>0 \cdot 15)$. At 12 weeks, two of 10 children in the negative group had residual abdominal pain compared with eight of 13 children in the positive group $(\mathrm{p}<0.05)$.

ULCER AND SYMPTOM RECURRENCE (TABLE 3) An 11 year old boy with persistent $H$ pylori infection was found to have early asymptomatic relapse of ulcer at 12 weeks. Three more children in the positive group were also found to have ulcer recurrence on endoscopy at six months, two of whom had complained of recurrent abdominal pain. None of the six children who remained negative at six months after initial clearance had developed a recurrent ulcer. In contrast, all three children with ulcer recurrence at six months had persistent $H$ pylori infection throughout the study period $(\mathrm{p}<0.05)$. All seven children in the group negative for $H$ pylori at six months were symptom free whereas six of 13 children in the positive group still had residual pain $(p=0.03)$.

\section{SIDE EFFECTS OF TREATMENT}

Five of the 23 children developed side effects on amoxycillin treatment: three with protracted diarrhoea and two with skin eruptions. These symptoms subsided spontaneously after cessation of treatment. There were no side effects observed related to cimetidine treatment.

HISTOLOGICAL GASTRITIS AND DUODENITIS $H$ pylori was detected in 66 of 89 available antral biopsy specimens, with 64 (97\%) having histo-

Table 3 Ulcer recurrence and $H$ pylori infection

\begin{tabular}{|c|c|c|c|c|}
\hline & \multicolumn{2}{|c|}{$H$ pylori at 12 weeks } & \multicolumn{2}{|c|}{$H$ pylori at 6 months } \\
\hline & Negative & Positive & Negative & Positive \\
\hline $\begin{array}{l}\text { Ulcer recurrence } \\
\text { No recurrence }\end{array}$ & $\begin{array}{r}0 \\
10\end{array}$ & $\begin{array}{r}1 \\
12\end{array}$ & $\begin{array}{l}0 \\
7^{*}\end{array}$ & $\begin{array}{r}3(3) \\
10(3)\end{array}$ \\
\hline
\end{tabular}

logical evidence of active chronic gastritis. In the remaining two without histological gastritis, coexistent duodenal biopsy specimens showed active duodenitis with $H$ pylori being detected in one. Eradication of $H$ pylori was associated with a significant improvement in the severity of histological gastritis (fig 2). The mean score for polymorphonuclear leucocytes for active gastritis in the clearance group at 12 weeks decreased from 1.50 before treatment to 0.30 after $H$ pylori eradication $(p<0.01)$. In contrast, the score in the persistently infected group fell only from 1.54 to 1.23 ( $p>0 \cdot 15$ ). Relapse of infection was associated with a significant worsening of active gastritis.

The grading of duodenitis also correlated significantly with $H$ pylori infection and histological active gastritis but did not correlate well with endoscopic ulcer healing (fig 3). The mean duodenitis score in the negative group at 12 weeks decreased from 1.80 before treatment to 0.60 after $H$ pylori eradication $(\mathrm{p}<0.01)$. In contrast, the duodenitis score in the positive group only fell from $1 \cdot 77$ to $1 \cdot 54(\mathrm{p}>0 \cdot 3)$.

Active duodenitis (intraepithelial neutrophils present) was found in 21 of $89(24 \%)$ duodenal biopsy specimens and gastric metaplasia on 26 occasions $(29 \%)$ of which 17 were associated with active duodenitis. The presence of $H$ pylor $i$ in duodenal mucosa was detected in 10 biopsy specimens, all showing histological evidence of active duodenitis. Furthermore, the presence of $H$ pylori in duodenal mucosa was confined to areas of gastric metaplasia.

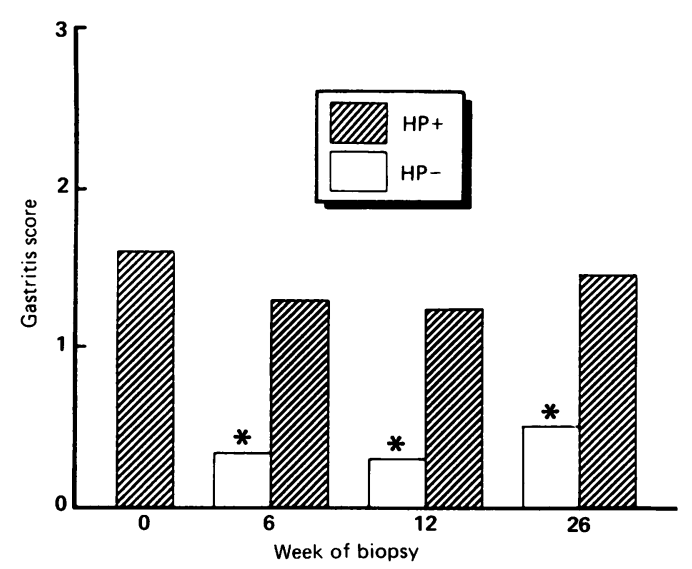

Figure 2 Effect of clearance, of $H$ pylori on gastritis score (number of polymorphonuclear leucocytes present).

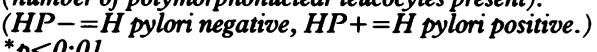




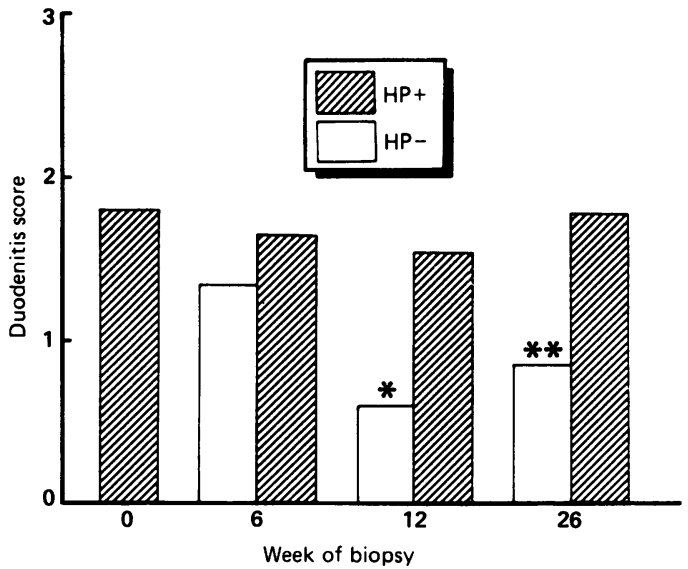

Figure 3 Effect of clearance of $H$ pylori on duodenitis score. ( $H P==H$ pylori negative, $H P+=H$ pylori positive.) ${ }^{*} p<0.01,{ }^{* *} p<0.05$.

\section{Discussion}

With the more frequent application of flexible upper endoscopy and hence more accurate diagnosis of lesions in the upper gastrointestinal tract, ${ }^{9}$ the detection of duodenal ulcer in children has increased appreciably in our practice in recent years. ${ }^{10}$ Although the use of $\mathrm{H}_{2}$ receptor antagonists has resulted in improved ulcer healing rates, recurrence of ulceration frequently occurs in over one third of patients. ${ }^{11} 12$ Marshall et al suggested that the presence of $H$ pylori infection was the most important aetiological factor in the pathogenesis of duodenal ulcer diathesis, as persistent $H$ pylori infection had been shown to be associated with significantly lower ulcer healing rates and a greater likelihood of ulcer recurrence. ${ }^{5}$ Similar studies of $H$ pylori associated duodenal ulcer in children and its treatment have not been reported previously. It has, however, been shown that in children with refractory duodenal ulcer, a six week course of amoxycillin achieved complete ulcer healing. ${ }^{13}$ This supports the hypothesis that microbial infection might also play an important part in the pathophysiology of peptic ulcer disease in childhood. In this study, all children who remained cleared of $H$ pylori after initial eradication had healed ulcers at six months without recurrent ulceration. In contrast, with failure of eradication of $H$ pylori only $33 \%$ of ulcers healed $(\mathrm{p}<0.02)$ and $50 \%$ recurred $(\mathrm{p}<0.05)$ during the six month period. Children in the group negative for $H$ pylori also experienced significantly less abdominal pain when compared with the persistently infected group.

As clearance of $H$ pylori has only been observed with antimicrobial treatment, ${ }^{2}{ }^{13-15}$ and spontaneous remission of $H$ pylori infection rarely occurred with use of $\mathrm{H}_{2}$ receptor antagonists alone, ${ }^{5}$ a combination of bactericidal and ulcer healing agents appears promising for treatment of duodenal ulceration in children. ${ }^{16}$ The use of amoxycillin to eradicate $H$ pylori infection has been disappointing in this study as fewer than half of the patients responded and relapse of infection was common. Furthermore, side effects including protracted diarrhoea and skin rash were troublesome. Although Oderda et al have reported the effective use of amoxycillin ( $50 \mathrm{mg} / \mathrm{kg} /$ day, twice the standard dosage) plus tinidazole for six weeks in eradication of $H$ pylori infection without mention of any side effects, ${ }^{17}$ it is unlikely that children in our locality can tolerate such a dose. It has recently been shown in adults that a combination of colloidal bismuth subcitrate and tinidazole was much more effective in healing ulcers and preventing recurrence than cimetidine alone. ${ }^{5}$ The use of bismuth preparations in children is, however, less desirable because of its possible neurotoxicity and arthrotoxicity in the growing child, and hence better therapeutic agents must still be sought.

The presence of $H$ pylori in the gastric antrum was strongly associated with active chronic gastritis and this is in accordance with most reports in adults. ${ }^{12} 13-15$ The severity of active gastritis correlated only with $H$ pylori state and significantly improved with eradication of infection. There is little understanding of the strong correlation between $H$ pylori associated gastritis and the presence of inflammatory infiltrates in the duodenum. It has been shown in this study that when $H$ pylori was present in the duodenum, this was always associated with active duodenitis. ${ }^{1819}$ According to the hypothesis that duodenitis represents a part of the pathophysiological spectrum of duodenal ulcer diathesis, ${ }^{8} 18$ persistent duodenitis associated with the persistence of $H$ pylori infection after endoscopic ulcer healing might well be of importance in the pathogenesis of duodenal ulcer diathesis and recurrence.

Gastric metaplasia was also found in duodenal mucosa in children in this study, although the frequency of $29 \cdot 2 \%$ was lower than most reported series in adults. ${ }^{718} 20$ It is interesting to note that the presence of $H$ pylori in the duodenum was invariably confined to areas of gastric metaplasia and was always associated with active duodenitis. ${ }^{8} 19$ As it has also been shown that $H$ pylori infection was associated with hypergastrinaemia and increased serum pepsinogen I concentrations, ${ }^{17} 21$ it may be postulated that $H$ pylori infection can act synergistically with acidpepsin induced gastric metaplasia to produce active duodenitis and mucosal damage which may culminate in ulceration.

In summary, our results document that persistent $H$ pylori infection is associated with persistence of gastritis and duodenitis despite endoscopic evidence of ulcer healing. Significantly more patients in the persistently infected group had unhealed ulcers with residual symptoms and ulcer recurrence. We support the proposals of Marshall $e t a l^{5}$ and recommend that detection and eradication of $H$ pylori deserves particular attention in the routine management of duodenal ulceration in childhood.

1 Warren JR, Marshall BJ. Unidentified curved bacilli on gastric epithelium in active chronic gastritis. Lancet 1983; gastric ep

2 McNulty CAM. The treatment of campylobacter-associated gastritis. Am f Gastroenterol 1987;82:245-7.

3 Cadranel S, Goossens H, DeBoeck M, Malengreau A, Rodesch P, Butzler J. Campylobacter pyloridis in children. Lancet 1986;i:735-6.

4 Drumm B, O'Brien A, Cutz E, Sherman P. Campylobacter 
pyloridis-associated primary gastritis in children. Pediatrics 1987;80:192-5.

5 Marshall BJ, Goodwin CS, Warren JR, et al. Prospective double-blind trial of duodenal ulcer relapse after eradication of Campylobacter pylori. Lancet 1988;ii:1437-42.

6 Arvind AS, Cook PS, Tabaqchali S, Forthing MJG. Oneminute endoscopy room test for Campylobacter pylori. minute endoscopy

7 Whitehead R. Gastritis. In: Whitehead R, ed. Mucosal biopsy of the gastrointestinal tract. 3rd Ed. London: Saunders, 1985:41-58.

8 Wyatt JI, Rathbone BJ, Dixon MF, Heatley RV. Campylobacter pyloridis and acid induced gastric metaplasia in the pathogenesis of duodenitis. $\mathcal{F}$ Clin Pathol 1987;40:841-8. 9 Gans SL, Ament M, Christie DL, et al. Pediatric endoscopy with flexible fiberscopes. F Pediatr Surg 1975;10:375-80.

10 Tam PKH, Saing H, Lau JTK. Diagnosis of peptic ulcer in children: the past and present. F Pediatr Surg 1986;21: 15-6.

11 Chiang BL, Chang MH, Lin ML, et al. Chronic duodenal ulcer in children: clinical observation and response to treatment. F Pediatr Gastroenterol Nutr 1989;8:161-5.

12 Tam PKH, Saing $\mathrm{H}$. The use of $\mathrm{H}_{2}$-receptor antagonist in the treatment of peptic ulcer disease in children. $f$ Pediatr treatment of peptic ulcer disease
Gastroenterol Nutr 1989;8:41-6.

13 Glupczynski Y, Burette A, Labbe M, et al. Campylobacter pylori-associated gastritis: a double-blind placebo-

See related paper on $\mathrm{p} 1278$. controlled trial with amoxycillin. Am $\mathcal{F}$ Gastroenterol 1988; 83:365-72.

14 Oderda G, Dell'Olio D, Morra I, Ansaldi N. Campylobacter pylori gastritis: long term results of treatment with amoxypylori gastritis: long term results of treat
cillin. Arch Dis Child 1989;64:326-9.

15 De Giacomo C, Maggiore G, Licardi G, Scotta MS, Fiocca R. Effects of antibacterial treatment of Campylobacter pyloriEffects of antibacterial treatment of Campylobacter pylor associa.

16 Perisic VN, Sarjamovic L. Campylobacter pylori, resistant duodenal ulcers, and antibiotic treatment. $\mathcal{F}$ Pediatr Gastroenterol Nutr 1988;7:934-5.

17 Oderda G, Vaira D, Holton J, Ainley C, Altare F, Ansaldi N. Amoxycillin plus tinidazole for Campylobacter pylori gastritis in children: assessment by serum IgG antibody, pepsinogen I, and gastrin levels. Lancet 1989;i:690-2.

18 Joffe SN, Lee FD, Blumgart LH. Duodenitis. Clin Gastroenterol 1978;7:635-50.

19 Johnston BJ, Reed PL, Ali MH. Campylobacter like organisms in duodenal and antral endoscopic biopsies: relationship to inflammation. Gut 1986;27:1132-7.

20 Kreuning J, Bosman FT, Kuiper G, Van der Wal AM Gastric and duodenal mucosa in 'healthy' individuals. Gastric and duodenal mucosa

21 Brady CE, Hadfield TL, Hyatt JR, Utts SJ. Acid secretion and serum gastrin levels in individuals with Campylobacter pylori. Gastroenterology 1988;94:923-7.

Long term survival with trisomy 18

Most children with trisomy 18 survive for only a short period. Approximately $70 \%$ survive the first month, $50 \%$ the first two months, and $10 \%$ the first year. A few survive into later childhood and survival into the 20s has been known. Van Dyke and Allen (Pediatrics 1990;85:753-9) describe six children who lived for more than a year. One was still alive at the age of 6 years but the other five had died at between 13 and 29 months of either heart disease or pneumonia. The main physical management problems in long term survivors are feeding problems, infection, congenital heart disease, and scoliosis due to hemivertebrae. The authors emphasise the importance of sympathetic psychosocial management for the family unit, the recognition of reactive and preparatory grief in the family, and the provision of a coordinated team approach.

ARCHIVIST 